\title{
A EDUCAÇÃO BÁSICA COMO DIREITO
}

\section{CARLOS ROBERTO JAMIL CURY}

Programa de Pós-Graduação em Educação da

Pontifícia Universidade Católica de Minas Gerais

crjcury.bh@terra.com.br

\begin{abstract}
RESUMO
Este artigo pretende explicitar um conceito novo que aparece na Lei de Diretrizes e Bases da Educação Nacional: educação básica. Por ser conceitualmente novo dentro de termos nem tão novos, ele precisa ser entendido em um novo quadro de referências. Além dessa dimensão, ele também é um direito e uma nova forma de organização da educação nacional. Enquanto conceito, ele auxilia na compreensão da realidade que o contém e que se apresenta sob novas bases. Como tal também significa alicerce e caminho. Como direito, a educação básica se impõe como uma ampliação do espectro da cidadania educacional. Finalmente, como nova organização, ela abrange três etapas: educação infantil, ensino fundamental obrigatório e ensino médio, progressivamente obrigatório. Tais etapas são constituídas de uma realidade única, diversa e progressiva. $\mathrm{O}$ artigo discute o significado dessa nova configuração conceitual, sua origem na Constituição Federal de 1988 e suas decorrências para a organização da educação nacional.

EDUCAÇÃO BÁSICA - DIREITO À EDUCAÇÃO - ENSINO OBRIGATÓRIO - LDB-BR: CONCEITO FUNDAMENTAL
\end{abstract}

\section{ABSTRACT}

BASIC EDUCATION AS A RIGHT. This article intends to explain a new concept which appears in the National Education Guidelines and Framework Law: basic education. As this is a conceptually new term among terms which are not so new, it needs to be understood within a new framework of references. Besides this dimension, basic education is also a right and a new way of organizing the Brazilian education. As a concept, it helps to understand the reality in which it is inserted and that presents itself under new basis. As such, it also means foundation and a path to be followed. As a right, it imposes itself as an extension of the spectrum of educational citizenship. Finally, as a new organization, it encompasses three phases: early childhood education, compulsory primary education and progressively compulsory secondary education. Such phases are made up of a unique, diverse and progressive reality. This article discusses the meaning of this new conceptual configuration, its origin in the Federal Constitution of 1988 and its consequences for the organization of the Brazilian education.

BASIC EDUCATION - RIGHT TO EDUCATION - COMPULSORY EDUCATION - LDB-BR: FUNDAMENTAL CONCEPTS 
A expressão "educação básica" no texto de uma Lei de Diretrizes e Bases da Educação Nacional - LDBEN - é um conceito, é um conceito novo, é um direito e também uma forma de organização da educação nacional.

Como conceito, a educação básica veio esclarecer e administrar um conjunto de realidades novas trazidas pela busca de um espaço público novo. Como um princípio conceitual, genérico e abstrato, a educação básica ajuda a organizar o real existente em novas bases e administrá-lo por meio de uma ação política conseqüente.

A capacidade de mobilização de uma idéia política reside justamente nos seus conteúdos abstratos. Aliás, a abstração é fonte fundamental de sua força, porque permite que os conteúdos de determinados princípios gerais possam ganhar redefinições inesperadas, e, portanto, a questão dos direitos será sempre uma construção imperfeita e inacabada. (Rego, 2006, p. 184)

E como a todo conceito corresponde um termo, vê-se que, etimologicamente, "base", donde procede a expressão "básica", confirma esta acepção de conceito e etapas conjugadas sob um só todo. "Base" provém do grego básis, eós e corresponde, ao mesmo tempo, a um substantivo: pedestal, fundação, e a um verbo: andar, pôr em marcha, avançar.

Como conceito novo, ela traduz uma nova realidade nascida de um possível histórico que se realizou e de uma postura transgressora de situações preexistentes, carregadas de caráter não democrático.

Como direito, ela significa um recorte universalista próprio de uma cidadania ampliada e ansiosa por encontros e reencontros com uma democracia civil, social, política e cultural.

E é aí que se situa o papel crucial do novo conceito inclusive como nova forma de organização da educação escolar nacional. Essa nova forma atingiu tanto o pacto federativo quanto a organização pedagógica das instituições escolares. Esse papel o é como tal porque à educação lhe é imanente o de ser em si um pilar da cidadania e o é inda mais por ter sido destinado à educação básica o condão de reunir as três etapas que a constituem: a educação infantil, o ensino fundamental e o ensino médio.

A educação básica é um conceito mais do que inovador para um país que, por séculos, negou, de modo elitista e seletivo, a seus cidadãos, o direito ao conhecimento pela ação sistemática da organização escolar. 
Resulta daí que a educação infantil é a raiz da educação básica, o ensino fundamental é o seu tronco e o ensino médio é seu acabamento. É dessa visão holística de "base", "básica", que se pode ter uma visão conseqüente das partes.

A educação básica torna-se, dentro do artigo $4^{\circ}$ da LDB, um direito do cidadão à educação e um dever do Estado de atendê-lo mediante oferta qualificada.

Nesse momento, cumpre inquirir pela origem desse conceito, desse conceito novo e dessa forma de organização.

Embora não constante do importante capítulo da Educação, na Constituição Federal - CF - de 1988, esse conceito se nutre do espírito do texto constitucional em cujo teor transparece o universalismo de vários direitos. A educação, dada sua inerência à cidadania e aos direitos humanos, foi, então, positivada como direito.

A educação básica é declarada, em nosso ordenamento jurídico maior, como direito do cidadão - dever do Estado.

A prática de declarar direitos significa, em primeiro lugar, que não é um fato óbvio para todos os homens que eles são portadores de direitos e, por outro lado, significa que não é um fato óbvio que tais direitos devam ser reconhecidos por todos. A declaração de direitos inscreve os direitos no social e no político, afirma sua origem social e política e se apresenta como objeto que pede o reconhecimento de todos, exigindo o consentimento social e político. (Chauí, 1989, p.20)

Este reconhecimento positivado, dentro de um Estado Democrático de Direito, tem atrás de si um longo caminho percorrido. Da instrução própria das primeiras letras no Império, reservada apenas aos cidadãos, ao ensino primário de quatro anos nos estados da Velha República, do ensino primário obrigatório e gratuito na Constituição de 1934 à sua extensão para oito anos em 1967 , derrubando a barreira dos exames de admissão, chegamos ao direito público subjetivo e ao novo conceito ora analisado (Fávero, 1996; Cury, 2000).

O artigo 205 da CF de 1988 é claro: "A educação, direito de todos e dever do Estado e da família, será promovida e incentivada com a colaboração da sociedade, visando ao pleno desenvolvimento da pessoa, seu preparo para o exercício da cidadania e sua qualificação para o trabalho". 
Essa definição, bela e forte, se vê reforçada pelo artigo $6^{\circ}$ da CF, como o primeiro dos direitos sociais.

Do direito nascem prerrogativas próprias das pessoas em virtude das quais elas passam a gozar de algo que Ihes pertence como tal. Estamos diante de uma proclamação legal e conceitual bastante avançada, mormente diante da dramática situação que um passado de omissão legou ao presente.

Do dever, dever de Estado, nascem obrigações que devem ser respeitadas tanto da parte de quem tem a responsabilidade de efetivá-las, como os poderes constituídos, quanto da colaboração vinda da parte de outros sujeitos implicados nessas obrigações (Cury, 2002).

A educação escolar, pois, é erigida em bem público, de caráter próprio, por ser ela em si cidadã. E por implicar a cidadania no seu exercício consciente, por qualificar para o mundo do trabalho, por ser gratuita e obrigatória no ensino fundamental, por ser gratuita e progressivamente obrigatória no ensino médio, por ser também a educação infantil um direito, a educação básica é dever do Estado.

E como se trata de um direito juridicamente protegido, em especial como direito público subjetivo no âmbito do ensino fundamental, é preciso que ele seja garantido e cercado de todas as condições.

Daí a LDB, o Plano Nacional de Educação e outros diplomas legais buscarem garantir esse direito (Castro, 1998).

Contudo, esse avanço jurídico, expresso em um novo conceitual, o é assim porque os que por ele lutaram se viram diante de uma dramática situação fática cuja existência é indicadora da permanência do velho.

$\bigcirc$ velho advém de longa data e de grave tradição em nosso país. Denunciavam-no os mais consistentes trabalhos desde Caio Prado Jr. e Sérgio Buarque de Hollanda, desde o ficcionismo realista de Machado de Assis e de Lima Barreto às análises clássicas de Raymundo Faoro, Francisco de Oliveira e de Wanderley Guilherme dos Santos e ao drama relatado pelas fotos de Sebastião Salgado, pelo ficcionismo atual de um Luiz Ruffato ou por meio de filmes como Cidade de Deus cujas produções confirmam os frios e cortantes números das estatísticas do Instituto Brasileiro de Geografia e Estatística - IBGE - , do Instituto de Pesquisa Econômicas Aplicadas - Ipea - e de órgãos internacionais.

No conjunto, tais análises e resultados não hesitam em contrastar a luta entre o velho e o novo tal como uma modernidade na economia e uma desi- 
gualdade social presa em formas autocráticas, autoritárias de mando político. A chamada à modernização conservadora permitia o avanço econômico pela manutenção de formas arcaicas de poder e cuja reiteração e repetição torna uma tragédia essa invasão do passado nas realidades presentes.

De todo modo, a realidade pré-88 já vinha conhecendo essa luta entre o velho e o novo, por já abrigar uma sociedade civil que deixava de ser "gelatinosa". Constituía-se uma nova esfera pública democrática, tanto para combater o poder governamental antidemocrático como para reivindicar as várias faces da democratização, aí incluída a do Estado. Novos sujeitos políticos surgiam com projetos diferentes para o futuro. Firmava-se a convicção de que o Brasil não tinha incompatibilidade com a organização da vida democrática e a democracia política poderia conviver com justiça social.

A ditadura que nos roubara a possibilidade de fazer política sob suas múltiplas expressões, confirmando a recorrente situação de que ela era privilégio de poucos, agora se via às voltas com a pujança de novos atores sociopolíticos.

O ordenamento jurídico, movido por essa onda contestatória e esperançosa, teria que incorporar conceitos novos, abstratos, que dessem forma à nova substância nascente.

Nesse específico sentido, a ordem real teria de ser atravessada no plano do direito positivo pela ordem normativa jurídica de tipo democrático. A intervenção normativa democrática ajudaria a cumprir uma função de ruptura, pelo menos de balizadora crítica dos velhos modos de ser petrificados na ordem consuetudinária. (Rego, 2006, p. 186)

É nesse momento de ruptura com a ordem existente que a CF a atravessa dando-Ihe novos contornos organizacionais e chamando essa mesma ordem para uma cidadania aberta a todos.

Assim, para fazê-la direito de todos, era imprescindível que houvesse algo de comum ou universal. É dessa inspiração, declarada e garantida na Constituição, que a educação escolar é proclamada direito. Dela se espera a abertura, além de si, para outras dimensões da cidadania e da petição de novos direitos.

Espera-se dessa escola comum, expressão estrutural da educação básica, a transmissão de conhecimentos necessários para a vida, a ereção de novos 
hábitos e novos padrões pelos quais se haveria de instituir, de modo organizado e sistemático, uma "vontade geral democrática" até então inexistente no país (Teixeira, 1996).

O status quo da escola existente até então não atendia à exigência de elevação quantitativa e qualitativa desses novos padrões da educação.

Ora, a LDB captou esse espírito e o traduziu pelo conceito de "educação básica", conceito novo expresso em uma declaração de direito de todos a ser realizado em uma educação escolar que contivesse elementos comuns. De um lado, o combate à desigualdade, à discriminação e à intolerância, de outro lado, o apontamento da condução da educação escolar pelo princípio, também novo, da gestão democrática.

Conquanto sob o termo educação fundamental', o texto do primeiro projeto de LDB, apresentado à Câmara dos Deputados em dezembro de 1988, dizia já sob o novo conceito:

Art. 16 - A educação fundamental abrange o período correspondente à faixa etária dos zero aos dezessete anos e tem por objetivo geral o desenvolvimento omnilateral dos educandos de modo a torná-los aptos a participar ativamente da sociedade.

Art. 17 - A educação fundamental compreende três etapas: educação anterior ao primeiro grau, de zero a seis anos; educação de primeiro grau, dos sete aos catorze anos; e educação de segundo grau, dos quinze aos dezessete anos.

O texto aprovado em junho de 1990, bem como a versão aprovada em dezembro de 1990, já modificava o termo para educação básica (cf. artigo 4²) e a tornava dever do Estado, inclusive para efeito de sua universalização em todos os seus níveis e modalidades.... Ambas as versões instituíam, no capítulo VII, o título "Da educação básica", cujo artigo 26 acolhia sua organização nas três etapas citadas. Por sua vez, o artigo 27 dizia: "A educação básica tem como

I. Como uma nova LDB era mandato constitucional ainda a ser efetivado, havia uma coexistência entre o avanço propiciado pela Constituição e o texto da Lei n. 4.024/6I com a redação dada pela Lei n. 7.044/82 e da Lei n. 5.540/68, inclusive na nomenclatura. Registre-se que a CF/88, no artigo 208, já distinguia a educação escolar sob a nomenclatura de ensino fundamental e de ensino médio. A etapa anterior já era subdividida em creche e pré-escola (Saviani, 1997; Cury et al., 1997). 
objetivo geral desenvolver o indivíduo, assegurar-lhe a formação comum indispensável para participar, como cidadão, da vida em sociedade, e fornecer-lhe meios para progredir no trabalho e em estudos posteriores".

O projeto dos senadores Darcy Ribeiro, Marco Maciel e Maurício Corrêa, de 1992, apesar de não incluir o conceito de educação básica, reconheceu, até por conta dos mandamentos constitucionais, as três etapas como um direito social. Contudo, esse texto diminui para cinco anos a duração obrigatória do ensino fundamental, embora ponha ênfase na jornada integral.

O texto do projeto n. I0I/93, advindo da Câmara dos Deputados, mantinha, em seu artigo $4^{\circ}$, o conceito de educação básica constituída pelas três etapas. O projeto dispunha de um capítulo próprio (Capítulo VII), “Da educação básica”, contendo, no artigo 27, a mesma redação supracitada.

O substitutivo do Senado ao projeto da Câmara, em 1994, tendo o senador Cid Sabóia como seu relator, também mantinha idêntico conceito no seu artigo $5^{\circ}$, com as três etapas, dispunha o capítulo VI, com o título de "Da educação básica", preservados os mesmos objetivos.

O substitutivo do senador Darcy Ribeiro, em relação ao texto do senador Cid Sabóia, separava a educação infantil da educação básica. A educação escolar dividir-se-ia em educação infantil, educação básica, composta de ensino fundamental e médio, e educação superior. Contudo, o ensino fundamental recuperava sua duração mínima de oito anos advinda da Constituição de 1967. Desse modo, o capítulo "Da educação básica" seria um conceito que abrangeria apenas o ensino fundamental e o ensino médio.

Na redação precedente àquela que seria a final, Darcy Ribeiro acata o conceito de educação básica (artigo 20 e 21) e o coloca sob as diretrizes explicitadas no artigo 24.

O relator final do projeto de LDB, senador José Jorge, ao apresentálo, reconhece a mobilização da sociedade civil e destaca como um "pilar da nova lei de diretrizes e bases da educação nacional a adoção do conceito de educação básica, que inclui a educação infantil, o ensino fundamental e o ensino médio".

O relator substitui, então, a redação que vinha da Câmara, supracitada, pela seguinte: "A educação básica tem por finalidades desenvolver o educando, assegurar-lhe formação comum para o exercício da cidadania e fornecer-lhe meios para progredir no trabalho e em estudos posteriores". 
O texto final aprovado pelo Congresso Nacional e sancionado pelo Presidente da República será o atualmente vigente, no qual o conceito de educação básica aparece. Tal conceito comparece nos Capítulos I e II, do Título V, e, ao longo do texto, 2 I vezes em 20 artigos. De modo constante, o termo educação básica se vê acompanhado, no conjunto dos artigos, do adjetivo "comum". Tal é o caso, por exemplo, da formação básica comum dos conteúdos mínimos das três etapas (inciso IV, do artigo $9^{\circ}$ ), da formação comum no artigo 22, da base nacional comum dos artigos 26, 38 e 64, da diretriz de respeito ao bem comum do artigo 27.

A ligação entre a dimensão básica e o conceito de comum, na educação, carrega um sentido próprio. Comum opõe-se a uma educação específica (do tipo ensino profissional), de classe (que constitua um privilégio) ou mesmo que carregue algum diferencial mesmo que lícito (escola confessional). A noção de comum associada à educação básica é um direito (em oposição a privilégio) e busca, em sua abertura universal, o aprendizado de saberes válidos para toda e qualquer pessoa, responde a necessidades educativas do desenvolvimento humano como um patrimônio cultural. $\bigcirc$ "comum" vai mais além de um "para todos", reportando-se a conhecimentos científicos, à igualdade, à democracia, à cidadania e aos direitos humanos (Teixeira, 1994).

Mas o conceito de educação básica também incorporou a si, na legislação, a diferença como direito. A legislação, mercê de amplo processo de mobilização, de disseminação de uma nova consciência, fez a crítica às situações próprias de minorias discriminadas e buscou estabelecer um princípio ético mais elevado: a ordem jurídica incorporou o direito à diferença.

A educação básica, por ser um momento privilegiado em que a igualdade cruza com a equidade, tomou a si a formalização legal do atendimento a determinados grupos sociais, como as pessoas portadoras de necessidades educacionais especiais, como os afrodescendentes, que devem ser sujeitos de uma desconstrução de estereótipos, preconceitos e discriminações, tanto pelo papel socializador da escola quanto pelo seu papel de transmissão de conhecimentos científicos, verazes e significativos.

Já os jovens e adultos que não tiveram oportunidade de se escolarizar na idade própria podem e devem ser sujeitos de um modelo pedagógico próprio e apoiados com recursos que os façam recomeçar sua escolaridade sem a sombra de um novo fracasso. 
As comunidades indígenas também devem ser sujeitos de um modelo próprio de escola, guarnecido por recursos e respeito à sua identidade cultural peculiar.

O reconhecimento das diferenças nesse momento da escolaridade é factível com o reconhecimento da igualdade.

É certo que as dificuldades para a realização de um ideal igualitário e universalista, propugnado pelo Estado de Bem-Estar Social, ensejaram o surgimento efetivo de lacunas, dando margem à separação da defesa do direito à diferença de sua base fundante no direito à igualdade. Sem este último, o direito à diferença corre o risco de políticas erráticas e flutuantes ao sabor de cada diferença. Por isso, a educação básica deve ser objeto de uma política educacional de igualdade concreta e que faça jus à educação como o primeiro dos direitos sociais inscrito na CF, como direito civil inalienável dos direitos humanos e como direito político da cidadania (Cury, 2005).

A educação básica, como direito, aprofundou-se no Brasil com a aprovação da Lei n. I I.274/06, pela qual o ensino fundamental obrigatório passou a durar nove anos, iniciando-se aos 6 anos de idade. A Lei n. 10.172/0 I, lei do Plano Nacional de Educação, esvaziada de seu suporte financeiro, ficou apenas em metas de "boa vontade" conquanto expressivas do quanto se poderia fazer nos dez anos de sua validade.

A emenda constitucional 53/06 do Fundo de Manutenção e Desenvolvimento da Educação Básica e Valorização dos Profissionais da Educação - Fundeb -, já aprovada e seguida da Lei n. I I.494/07, lei de sua regulamentação, podem representar uma nova definição de educação básica.

Elas representam uma mudança tanto na composição e distribuição dos recursos em educação quanto na abertura de mais portas para o atendimento do ensino médio, da educação infantil e da Educação de Jovens e Adultos EJA.

Financiar todas as etapas da educação básica, com aporte progressivo da União, é reforçar o estatuto da federação que tem como um de seus objetivos fundamentais, segundo o artigo $3^{\circ} \mathrm{III}$, da CF/88: "erradicar a pobreza e a marginalização e reduzir as desigualdades sociais e regionais". Entretanto, a expansão qualificada da educação básica como um todo terá que contar com um aumento da relação entre Produto Interno Bruto e Educação e com uma boa gestão dos recursos em todos os escalões. 
Por ser um serviço público, ainda que ofertado também pela iniciativa privada, por ser direito de todos e dever do Estado, é obrigação deste interferir no campo das desigualdades sociais e, com maior razão, no caso brasileiro, no terreno das hierarquias sociais, como fator de redução das primeiras e eliminação das segundas, sem o que o exercício da cidadania ficaria prejudicado a priori.

A função social da educação assume a igualdade como pressuposto fundamental do direito à educação, sobretudo nas sociedades politicamente democráticas e socialmente desejosas de maior igualdade entre as classes sociais e entre os indivíduos que as compõem e as expressam.

Essas são as exigências que o direito à educação traz, a fim de democratizar a sociedade brasileira e republicanizar o Estado.

\section{REFERÊNCIAS BIBLIOGRÁFICAS}

BRASIL. Constituição Federal do Brasil. Brasília: Senado, 1988.

CASTRO, M. L. O. de. A Educação na Constituição de 1988 e a Lei de Diretrizes e Bases da Educação Nacional. Braślia: André Quincé, 1998.

CHAUÍ, M. Direitos humanos e medo. In: FESTER, A. C. R. (org.) Direitos humanos e... São Paulo: Brasiliense, 1989. p. 15-35.

CURY, C. R. J. Direito à educação: direito à igualdade, direito à diferença. Cadernos de Pesquisa, n. I I6, p.245-262, jun. 2002.

A Educação básica no Brasil. Educação e Sociedade, v.23, n.80 esp., p. 169-

201, 2002a.

A Educação como desafio na ordem jurídica. In: LOPES, E. M. T.; GREIVE,

C.; FARIA FILHO, L. (orgs.) 500 anos de educação no Brasil. Belo Horizonte: Autêntica, 2000, p.567-584.

Os Fora de série na escola. Campinas: Autores Associados, 2005.

CURY, C. R. J. et al. Medo à liberdade e compromisso democrático: LDB e Plano Nacional de Educação. São Paulo: Editora do Brasil, 1997.

FÁVERO, O. (org.) A Educação nas constituintes brasileiras: 1823-1988. Campinas: Autores Associados, 1996.

MALISKA, M. A. O Direito à educação e a Constituição. Porto Alegre: Antonio Fabris, 200 I . 
REGO, W. D. L. Intelectuais, Estado e ordem democrática: notas sobre as reflexões de Florestan Fernandes. In: RIDENTI, M.; BASTOS, E. R; ROLLAND, D. (orgs.) Intelectuais e Estado. Belo Horizonte: Ed. UFMG, 2006, p. 184.

SAVIANI, D. A Nova lei da educação: LDB, trajetória, limites e perspectivas. Campinas: Autores Associados, 1997.

TEIXEIRA, A. Educação é um direito. Rio de Janeiro: UFRJ, 1996.

Educação não é privilégio. Rio de Janeiro: UFRJ, 1994.

Recebido em: novembro 2007

Aprovado para publicação em: dezembro 2007 